\title{
USAGE INTENTION FOR REAL-TIME PRODUCTION CAPABILITY INFORMATION SYSTEM
}

Tsuen-Ho Hsu

National Kaohsiung First University of Science and Technology No. 1, University Rd., Yanchao Dist., Kaohsiung City, Taiwan

thhsu@nkfust.edu.tw

Ling-Zhong Lin

Shih Chien University

No. 200, University Rd., Neimen Dist, Kaohsiung City, Taiwan

ling@mail.kh.usc.edu.tw

Chih-Kwang Yang

National Kaohsiung First University of Science and Technology No. 1, University Rd., Yanchao Dist., Kaohsiung City, Taiwan

u9428910@nkfust.edu.tw

\begin{abstract}
With the prosperity and the growing trend of online information system applications, consumers and business alike have been changing their behavioral models for obtaining information. This brings enormous commercial opportunities to the catering industry. In order to promote its competitive advantages, Napoli Pizza, a chain restaurant in Taiwan, implemented a real-time kitchen production capability information system (e-KS). This research aims at helping Napoli Pizza to identify factors affecting employees' attitude toward e-KS usage intention. The results show that employees have positive impressions and evaluations of e-KS, and the most influential factor is employees' "attitude toward using", which has a significant effect on their usage intention.
\end{abstract}

Keywords: Chain Restaurant, Real-time Production Capability Information System, Usage Intention, Acceptance model

\section{INTRODUCTION}

The amount of annual pizza sales in Taiwan is estimated at between US\$150 - \$167 million (the currency is US dollar hereafter). Three major 
pizza chain restaurants, Pizza Hut, Domino's Pizza, and Napoli Pizza occupy most of the market share and the price strategies of franchisors are different. Pizza Hut and Domino's Pizza, which own 127 restaurants and 115 restaurants respectively, both adopt a strategy of high price, while Napoli Pizza, which has more than 92 restaurants, applies a middle price strategy. The average consumer spending at Pizza Hut or Domino's Pizza is $\$ 18.3$ and the average customer spending at Napoli Pizza is about $\$ 9.3$ per consumption. In addition, some small pizza chain restaurants, such as 50 Dollar Pizza sells a pizza for only $\$ 1.8$, thus applying a low price strategy, have taken over some market share. This suggests that the Taiwan pizza market has entered a hyper competitive and saturated era. While other pizza business owners explore strategies in price, product content, and service model for more business opportunities, Napoli Pizza is looking for novel approaches to gain way to gain an edge in the market.

With partial funding from the Department of Commerce, Ministry of Economic Affairs (MOEA, R.O.C.) and consultation with the Institute for Information Industry in Taiwan, Napoli Pizza introduced e-KS in July 2010. The aim of the system is to increase management efficiency and effectiveness, to motivate customers and to develop a leading competency over its competitors.

The e-KS provides users with the real-time status of an order. This facilitates better production scheduling for kitchen managers; allows delivery staff to get a delivery deadline, plan a delivery route and avoid late delivery complaints; allows a customer to get information on wait time, and as a result, can decrease anxiety. The system also provides an enjoyable ordering environment for customers, as customers can search for product and promotion information on the digital menu with the on-site touch screen. The e-KS integrates orders from a POS or central ordering center and monitors production capability at the same time, so that a kitchen manger can optimize operations. In addition, chain restaurants can form a synergic group in which each restaurant acts as a backup for others.

To successfully implement a new information system, employees play a very critical role. Consequently, the purpose of the study is to explore, by applying the Technology Acceptance Model (TAM) ${ }^{1}$, employees' acceptance behavioral intention to use e-KS, and to understand the key factors of successful implementation. The study will provide valuable reference regarding system development for the management of Napoli Pizza and also other business owners. 


\section{THEORETICAL FRAMEWORK}

TAM is a model used in the field of study of user acceptance of technology. Fred Davis first proposed a conceptual model in his doctoral thesis at the MIT Sloan of Management. Davis proposed that actual system use is a response that can be explained or predicted by user motivation, while user motivation is directly influenced by external stimulus such as a system's features and capabilities ${ }^{1}$.

Davis further refined his conceptual model, by relying on Fishbein and Ajzen's Theory of Reasoned Action (TRA) ${ }^{2}$ and other related research studies, into TAM, the Technology Acceptance Model ${ }^{3,4}$. In this model, Davis maintained the argument of TRA that the intention of an action is the antecedent of actual behavior, thus, the actual system use is influenced by the user's attitude toward use. Then, applying this to the field of technology acceptance, Davis added two major beliefs, "perceived usefulness" and "perceived ease of use" to the model. He argued that the attitude toward use was influenced by these two major beliefs. Finally, both of these two beliefs were hypothesized to be influenced by system design characteristics. This is to say that the more the users perceive information technology use as beneficial to their job (attitude), the higher their willingness to use the technology (behavior intention). Nevertheless, external factors such as attractive technology designs including panel control thru images or touch screens, friendly machine user interfaces, or mechanisms such as training, documents, and consultants also affect users' usage intention ${ }^{4,5,6}$.

TAM provides a theoretical basis to understand how external variables influence users' internal beliefs, attitudes, and intentions and further affect users' behavior on information technology. The model looks at users' acceptance behavior and also analyzes the factors that influence users' usage intention on a new information technology. TAM has been extensively applied in the following ways: (a) to study an organization or cross-organization behavior, (b) to help an organization make a decision when selecting a suitable software package, and (c) to explore key success factors of an information system ${ }^{5}$.

In addition, TAM was selected as the theoretical framework for this study for the following reasons: first, it provides explanation and prediction of how an individual decides to adopt a new technology; second, TAM has been extensively and empirically tested and refined for the adoption and application of many new technologies ${ }^{5,7,8,9,10}$; and third, the model studies users' acceptance behavior and also analyzes the factors that influence users' usage intention on a new information technology; and it is a theory that uses parsimony principle to explain and study people's acceptance on different technology applications ${ }^{6}$. In short, TAM was chosen as the theoretical 
framework because of its history as a reliable measurement instrument, its theoretical conciseness, and its empirical stability $6,11,12,13$.

In the TAM framework, some external variables can affect users' attitude and behavior toward use of the new technology, which are intermediated by perceived ease of use and perceived usefulness. Examples of external variables are personal features (e.g., users' computer self-efficacy and previous adoption experience), system features (e.g., quality of the new system, its design features and functionality), and organizational features (e.g., company policy, top management support, and training) ${ }^{14}$. In further research with TAM, Davis and his colleagues ${ }^{9,15}$ have identified several affective features for those external variables that unavoidably have an impact on users' usage intention ${ }^{4,5,6}$. A large amount of literature also verified the external variables of TAM $^{5,16,17,18,19,20}$ and concluded that similar external variables such as personal features, system features, and organizational features were the determining factors.

In this study, we hypothesized that system quality and company policy were external variables of TAM.

\section{CONSTRUCT E-KS}

The Real-time Kitchen Production Capability Information System, abbreviated as e-KS, is a smart shop system developed for Napoli Pizza. It is one of the Special Intelligence Shop Development Projects run by the Department of Commercial, Ministry of Economic Affairs and Institute of Information Industry in Taiwan. There are five functions in the e-KS as follows:

1. Flow for meal-preparation: After customers order a meal, either on-site from the smart touch system by themselves or by a clerk, or by ordering by phone and subsequent data-entry through the POS by staff, the order information flows to the smart kitchen system. Kitchen staff are provided with quantity and meal type of the order and start to prepare the meal.

2. Flow for meal-delivery: The system calculates and shows a deadline for each order. With the deadline information, the delivery staff can arrange the delivery process to avoid a late delivery and hence reduce customer complaints.

3. Flow for settling accounts: The system creates an account of order information of meal type, quantity, ordering time and deadline and settles the account after cash is received. 
4. Flow for real-time production capability display: The system monitors a store's real-time production capability, integrates orders from a central ordering center, and arranges an optimal production schedule.

5. Digital menu (electronic menu): The system provides a digital menu so that customers can easily search for a meal type on the screen.

The e-KS also provide on-line search function for customer to inquire about store information such as store location, meal order status, and time until an order is ready. By integrating the ordering system from a central order center, the real-time production capability provides information to help managers utilize each store's capability and arrange a better production schedule, which helps to avoid customer complaints from late deliveries and achieve cost reduction and management effectiveness for the pizza chain stores.

Due to the intense competition in the pizza industry in Taiwan, the Napoli Pizza chain stores needed a novel approach to motivate customers. By employing the e-KS, Napoli Pizza provided users with an information application to its smart shop, and also delivered a novel experience for the customers by providing an enjoyable ordering environment. Further, e-KS provides a customer with the real-time status of an order, which will decrease waiting anxiety and increase customer satisfaction. To sum up, the Napoli Pizza chain can gain a significant competitive advantage by successfully implementing the new e-KS system.

\section{HYPOTHESIS DEVELOPMENT}

This study aims to probe employees' attitude toward e-KS based on empirical research references and relevant theory, such as the TAM, to build an integrated research model.

First, according to previous studies system quality plays a primary role in the success of an information system ${ }^{21,22,23}$. Some studies' findings show that information quality had an effect on perceived ease of use and perceived usefulness $6,24,25$. Also, system quality is important in user beliefs and satisfaction ${ }^{26,27,28}$. Likewise, findings from some studies about on-line shopping showed that system quality had a relatively strong and positive effect on perceived ease of use and perceived usefulness ${ }^{29,30}$. Thus, the following hypotheses are proposed.

Hypothesis 1: e-KS system quality positively affects perceived usefulness of employees.

Hypothesis 2: e-KS system quality positively affects perceived ease of use of employees. 
Most studies on technology acceptance showed that perceived ease of use directly influenced perceived usefulness and attitude towards use ${ }^{29,31-33}$. In particular, Davis ${ }^{4}$ stated that "through perceived usefulness, perceived ease of use indirectly influences attitude towards use and acceptance intention, which in turn clearly shows that perceived ease of use is the antecedent of perceived usefulness". Therefore, a third hypothesis was proposed.

Hypothesis 3: Perceived ease of use of e-KS positively affects perceived usefulness of employees.

The main dependent variable in studies building on the TAM is intention to use, which is defined as the likelihood that an individual will use a technology 8,10 . The main antecedent is a person's attitude towards using a technology $\mathrm{y}^{4,7}$, which is defined as the degree to which using a technology is assessed positively or negatively by an individual. A positive relationship between these two constructs-intention to use and attitude towards using a technology - has been found in previous studies ${ }^{34,35}$. For example, Turner and his colleague's work identified the results of 79 relevant empirical studies in 73 articles showing that behavior intention is likely to be correlated with actual usage.

This structure was adopted in our research model and hypothesized that attitude towards using e-KS serves has a determinant influence of the intention to use e-KS. Moreover, from Davis' work and some previous studies ${ }^{4,36}$, both perceived usefulness and perceived ease of use served as the antecedents of the attitude toward use. Accordingly, the following hypotheses were proposed.

Hypothesis 4: Perceived usefulness of e-KS positively affects attitude toward use of e-KS by employees.

Hypothesis 5: Perceived ease of use of e-KS positively affects attitude toward use by employees.

In the work of Davis et $\mathrm{al}^{7}$, they omitted the relation of subjective norm's effect on intention and the perceived usefulness ease of use because they found that a subjective norm had no significant effect on these variables. However, they did call for additional research to investigate the settings and conditions underlying the impact of social influences on usage intention. In the work of Hartwick and Barki ${ }^{18}$, they found that the influence of subjective norm on intention was significant in the mandatory groups of respondents while insignificant in voluntary groups. Since company policies are mandatory, the following hypothesis was constructed.

Hypothesis 6: Company policy positively affects attitude toward using e-KS for employees. 
Attitude towards use had a direct effect on actual use ${ }^{4}$. Further research on TAM has also exhibited strong empirical support for a positive relationship between attitude towards use and actual use ${ }^{7,16,37}$. Thus, one last hypothesis was proposed.

Hypothesis 7: The attitude toward using e-KS positively affects behavioral intention of use for employees.

\section{METHODOLOGY}

\subsection{Operational Definition}

System quality is defined as connection speed, system reliability, and system satisfaction for e-KS users. Also, according to Davis and other scholars ${ }^{4,6}$, perceived ease of use is a person's belief regarding use a specific system as done without applying too much effort. Perceived ease of use is denoted as the extent an employee believes that e-KS is easy to use. Furthermore, Davis ${ }^{4}$ identified that perceived usefulness is a user's subjective thinking on whether using an information technology will be beneficial to their job performance including an increase in work and learning speed, productivity, and efficiency. Perceived usefulness is signified as employee's consideration that the use of e-KS can reduce workload or manpower, and operation error, and also create an information integration effect and reduce customer wait times.

Moreover, Simonson et al. ${ }^{20}$ proposed that attitude, experience, cognition, and learning pattern are four major indicators to reinforce a user's ability to learn how to use an information technology, and attitude is the most important indicator. Attitude toward use is construed as the degree of employees' positive or negative evaluation on the use of e-KS. In addition, company policy is described as whether employees will increase their willingness to use e-KS under company regulations. It acts as an external variable to influence perceived usefulness and perceived ease of use and further to affect behavior intention. In terms of behavior intention, Ajzen ${ }^{17}$ assumed that behavior intention is a person's intentional intensity to perform a certain behavior. It is often used to predict or explain actual behavior performance. Behavior intention is delineated as an employee's subjective willingness to use e-KS.

\subsection{The Questionnaire}

The questionnaire was divided into six dimensions including system quality (SQ), perceived ease of use (PE), perceived usefulness (PU), attitude toward using (A), behavioral intention to use (BI), and company policy $(\mathrm{CP})$. The study adopted Davis's viewpoints ${ }^{4}$ and developed fifteen measurement items to measure system quality, perceived ease of use, and perceived 
usefulness respectively. The study used Simonson et al.'s viewpoints ${ }^{20}$ and developed five measurement items to measure attitude toward using. Meantime, the study applied Lin \& Lu's viewpoints ${ }^{19}$ to develop five measurement items to measure company policy. Additionally, the study utilized Ajzen's ${ }^{17}$ viewpoints to develop five measurement items to measure behavior intention. The questionnaire also includes demographic survey items. All measurement items of the questionnaire employed a 5-point Likert's scale $(1=$ very disagree, $5=$ very agree $)$.

\section{FINDINGS}

\subsection{Data Reliability}

Split-half correlations and Cronbach's alpha coefficients were taken to test statistical stability. For the importance scale, the split-half correlations were .87 , while the alpha coefficient was .91 . For the evaluation scale, the split-half correlations were .89, and the alpha coefficient was .94. Finally, the Kaiser-Myer-Olkin statistics of sampling adequacy were calculated, with an outcome of .96 for the importance scale and .92 for the evaluation scale. In total, these statistics indicate internal rigor based on an adequate sampling, and thereby merit further analysis.

\subsection{Descriptive Characteristics of the Respondents}

This study investigated whether e-KS has been accepted by Napoli Pizza employees. The main object focused on the effects of administration support, time factors and equipment resources after building e-KS. Eight Napoli Pizza restaurants were surveyed by questionnaires. It took one month to distribute and collect the questionnaires. The informants filled out the questionnaire during work shifts. Of 220 questionnaires distributed to the employees, 212 completed questionnaires were collected. Of these, 204 were valid, yielding a return rate of about $96 \%$. The survey was given to both full-time and part-time workers.

Table 1 lists the analytical results of the sample profile. Male and female each consist of about half of the sample population. Most of the respondents were in an age range of 20-29 years old (74\%), university educated (45.6\%), and had 3 years or less work experience. 
Table 1. Summary of participants' profile

\begin{tabular}{ccccc}
\hline Characteristics & Descriptions & Statistics & $(\%)$ \\
\hline \multirow{2}{*}{ Gender } & Male & 107 & 52.45 & $\%$ \\
& Female & 97 & 47.55 & $\%$ \\
\hline \multirow{4}{*}{ Age (years) } & $20-29$ & 151 & 74.00 & $\%$ \\
& $30-39$ & 39 & 19.10 & $\%$ \\
& $40-49$ & 6 & 2.90 & $\%$ \\
& $50-59$ & 1 & 0.50 & $\%$ \\
& 60 and order & 6 & 2.90 & $\%$ \\
\hline \multirow{5}{*}{ Education } & Senior high & 44 & 21.60 & $\%$ \\
& school & 56 & 27.50 & $\%$ \\
& College & 93 & 45.60 & $\%$ \\
& University & 7 & 3.40 & $\%$ \\
\hline \multirow{5}{*}{ Experience } & Graduate & 118 & 57.80 & $\%$ \\
(years) & Below 3 & 49 & 24.00 & $\%$ \\
& $3-7$ & 11 & 5.40 & $\%$ \\
& $7-10$ & 19 & 9.30 & $\%$ \\
& $10-15$ & 7 & 3.40 & $\%$ \\
\hline
\end{tabular}

\subsection{Measurement Model Analysis}

This study adopted a two-stage approach for the structural equation model. The first stage determined the adequacy of the measurement model. The second stage constructed the structural equation model itself. This procedure achieves a reliable measure because it avoids interaction between the measurement and structural models, as suggested by Anderson and Gerbing ${ }^{38}$.

Discriminant validity analysis was performed by limiting the correlation coefficient of the paired dimensions to 1 then performing a Chi-square variance test of the limited and unlimited measurement patterns. If the Chi-square value of the limited pattern exceeds that of the unlimited measurement pattern and is statistically significant, then both dimensions have discriminant validity. Table 2 lists the results of discriminant validity analysis for all dimensions. The Chi-square values of limited patterns exceed those of unlimited patterns and reach statistical significance, and so confirm discriminant validity for all dimensions. 
Table 2. Discriminate validity analysis

\begin{tabular}{ccccc}
\hline Pattern & $\chi^{2}$ & d.f. & \multicolumn{2}{c}{$\Delta \chi^{2}$} \\
\hline Unlimited & 238.69 & 48 & \multicolumn{2}{c}{-} \\
measurement pattern & 312.53 & 47 & 84.25 & $* * *$ \\
SQ-PE & 423.67 & 47 & 132.61 & $* * *$ \\
SQ-PU & 443.81 & 47 & 174.82 & $* * *$ \\
SQ-ATT & 458.89 & 47 & 201.38 & $* * *$ \\
SQ-BI & 337.94 & 47 & 238.42 & $* * *$ \\
SQ-CP & 367.82 & 47 & 86.39 & $* * *$ \\
PE-PU & 385.75 & 47 & 173.78 & $* * *$ \\
PE-ATT & 269.57 & 47 & 261.19 & $* * *$ \\
PE-BI & 554.39 & 47 & 78.43 & $* * *$ \\
PE-CP & 632.12 & 47 & 158.96 & $* * *$ \\
PU-ATT & 379.63 & 47 & 237.66 & $* * *$ \\
PU-BI & 256.84 & 47 & 179.85 & $* * *$ \\
PU-CP & 479.66 & 47 & 248.52 & $* * *$ \\
ATT-BI & 329.83 & 47 & 93.87 & $* * *$ \\
ATT-CP & 532.11 & 47 & 178.57 & $* * *$ \\
BI-CP & & 47 &
\end{tabular}

Note: System Quality (SQ), Perceived Ease of Use (PE), Perceived Usefulness (PU), Attitude toward Using (ATT), Behavioral Intention to Use (BI), Company Policy (CP), ${ }^{*} p<$ $0.05, * * p<0.01, * * * p<0.001$.

\subsection{Structural Model Analysis}

Since the reliability and validity of all investigated dimensions were acceptable, using a single measurement indicator rather than multiple measurement indicators was considered viable. The dimension scores of system quality, perceived ease of use, attitude toward using, behavioral intention to use, and company policy were first averaged, and then used as measurement indicators during the structural model analysis. 
Table 3. Overall pattern fitness of structural model

\begin{tabular}{ccc}
\hline Fitness indicators & Ideal value & This study \\
\hline & Absolute fitness test & \\
\hline$\chi^{2} / d f$ & $<3$ & 1.772 \\
GFI & $>0.8$ & 0.921 \\
AGFI & $>0.8$ & 0.859 \\
RMSEA & $<0.08$ & 0.063 \\
\hline \multicolumn{3}{|c}{ Incremental fitness test } \\
RFI & $>0.9$ & 0.943 \\
IFI & $>0.9$ & 0.908 \\
TLI & $>0.9$ & 0.974 \\
CFI & $>0.9$ & 0.958 \\
& $>0.9$ & 0.974 \\
\hline PCFI & Reduced fitness test \\
PNFI & $>0.5$ & 0.609 \\
\hline
\end{tabular}

Among the overall pattern fitness indicators, for Chi-square/d.f. = $1.722, \mathrm{GFI}=0.921, \mathrm{NFI}=0.943, \mathrm{CFI}=0.974, \mathrm{PCFI}=0.609$ and $\mathrm{RMSEA}=$ 0.063 , all indicators were tenable, as Table 3 shows. Internal structural fitness was assessed using the following criteria: (1) individual reliability exceeding $0.5,(2)$ reliability of potential variable combination exceeding 0.7 , and (3) AVE of potential variance exceeding 0.5. The analytical results suggested that all indicators were tenable; thus this pattern exhibited good internal structural fitness.

\subsection{Assessment of the Hypothesized Relationship}

Hypotheses 2, 3, 4, 6 and 7 were significant, but Hypotheses 1 and 5 were not (Table 4 and Figure 1). The perceived usefulness of e-KS revealed the strongest influence on employee's attitude $\left(\gamma_{1}=\mathrm{OC}\right)$. Thus, managers should provide, for example, usefulness knowledge about e-KS and evidence of workload reduction to increase employee awareness and appreciation of this new information technology. Second, employees' attitude toward use $\left(\beta_{21}=0.87\right)$ positively influences behavioral intention to use e-KS. Third, interaction between system quality of e-KS increases employees perceived ease of use $\left(Y_{12}=0.65\right)$. Employees perceived usefulness of e-KS is influenced by the perception of perceived ease of use, such as that e-KS divides tasks into more manageable proportions, which has a positive impact. To maximize positive employee behavioral intention to use, the likelihood of establishing positive employees attitude depends on positive interaction relationships among company policy, system quality and 
employees perceived ease and usefulness of use. When employees perceived that the system is easy to use, the interaction between usefulness and system quality $\left(\gamma_{22}=0.22\right)$ has the most potential for boosting an employee's attitude toward use.

Table 4. Overall theory pattern analysis

\begin{tabular}{|c|c|c|c|c|}
\hline Independent & Dependence & $\begin{array}{l}\text { Direct } \\
\text { Effect }\end{array}$ & $\begin{array}{l}\text { Indirect } \\
\text { Effect }\end{array}$ & $\begin{array}{l}\text { Overall } \\
\text { Effect }\end{array}$ \\
\hline \multicolumn{5}{|c|}{ System Quality } \\
\hline & $\begin{array}{l}\text { Perceived } \\
\text { Usefulness }\end{array}$ & $0.22 * * *$ & 0.26 & 0.28 \\
\hline & $\begin{array}{c}\text { Perceived Ease of } \\
\text { Use }\end{array}$ & $0.65^{* * *}$ & - & $0.65 * * *$ \\
\hline & $\begin{array}{l}\text { Attitude toward } \\
\text { Using }\end{array}$ & - & 0.23 & 0.23 \\
\hline & $\begin{array}{l}\text { Behavioral } \\
\text { Intention to Use }\end{array}$ & - & 0.20 & 0.20 \\
\hline \multicolumn{5}{|c|}{ Perceived Ease of Use } \\
\hline & $\begin{array}{l}\text { Perceived } \\
\text { Usefulness }\end{array}$ & $0.40^{* * *}$ & - & $0.40 * * *$ \\
\hline & $\begin{array}{l}\text { Attitude toward } \\
\text { Using }\end{array}$ & -0.03 & 0.36 & 0.32 \\
\hline & $\begin{array}{l}\text { Behavioral } \\
\text { Intention to Use }\end{array}$ & - & 0.28 & 0.28 \\
\hline \multicolumn{5}{|c|}{ Perceived Usefulness } \\
\hline & $\begin{array}{l}\text { Attitude toward } \\
\text { Using }\end{array}$ & $0.90^{* * *}$ & - & $0.90 * * *$ \\
\hline & $\begin{array}{l}\text { Behavioral } \\
\text { Intention to Use }\end{array}$ & - & 0.78 & 0.78 \\
\hline \multicolumn{5}{|c|}{ Company Policy } \\
\hline & $\begin{array}{l}\text { Attitude toward } \\
\text { Using }\end{array}$ & $0.18 * *$ & - & $0.18 * *$ \\
\hline & $\begin{array}{l}\text { Behavioral } \\
\text { Intention to Use }\end{array}$ & - & 0.15 & 0.15 \\
\hline \multicolumn{5}{|c|}{ Attitude toward Using } \\
\hline & $\begin{array}{c}\text { Behavioral } \\
\text { Intention to Use }\end{array}$ & $0.87 * * *$ & & $0.87 * * *$ \\
\hline
\end{tabular}

Note: $* p<0.05, * * p<0.01, * * * p<0.001$ 


\section{CONCLUSIONS}

This study found that when employees perceive that e-KS is helpful in promoting work efficiency, the chance that they will use the system is great. When employees perceive e-KS as very easy to use, this will affect their perception of usefulness about the system. As such, when Napoli Pizza develops e-KS, the company has to be very careful about system friendliness and align it with employee work requirements that solve their problems and reduce their workload. e-KS can bring benefits to the company and advance employees' usage intention. Furthermore, the results imply that the company has to raise employee recognition on perceived ease of use and perceived usefulness to increase their usage intention on e-KS. In other words, when employees perceive that e-KS is helpful and easy to use, their willingness to use the system will be enhanced. Accordingly, employee perceived usefulness can be promoted by emphasizing system quality and providing training to store clerks. In addition, in order to promote employee usefulness recognition, the company needs to actively respond to employee feedback and in due course, this will improve their willingness and confidence and further build up a consensus on ease and usefulness of the system.

This study showed that the hypothesis about the influence of perceived ease of use on employee's attitude toward use did not exist and as such deserves some additional discussion. Most of the e-KS users in Napoli Pizza come from a young generation, $93.1 \%$ are between 20 to 39 years old (Table 1). This is a generation of computer users. As such, whether the system is easy to use does not influence their attitude toward use. However in other situations, such as in Joeng and Lee's work ${ }^{36}$, when the respondents are older, whether they perceive the system is easy to use becomes a more significant factor in their attitude toward use.

In the preliminary and introductory stage, Napoli Pizza only implemented e-KS in eight stores because it is a new technology and user feedback and experience are necessary for system tuning and modification. For the majority of employees the system is still unfamiliar, and their knowledge about e-KS is from dialogue with colleagues. The company should reinforce communication with its employees and arrange some workshops to provide more hands-on experience with the system for their employees. These experience activities can increase employee perceptions of usefulness and reduce stereotypes and resistance to the new information system. The study results also indicate that perceived usefulness significantly and positively affects attitude toward use, and attitude toward use can influence behavioral intention. Therefore, in order to boost employee usage intention, the company also needs to emphasize system 
quality from the system designer so as to make users realize the system is stable and trustworthy.

Finally, the results show that company policy will moderate employee attitude toward use and behavioral intention. When the company tries hard to promote the system, this will positively affect employee attitude toward use and as a result, change their behavioral intention. This implies that setting up a positive usage attitude for employees is a crucial factor in whether e-KS will succeed or fail. This also suggests that the company can spend fewer resources and create better performance if the company pays more attention to employee mindsets, require the application and encourage acceptance of the new information technology. In this scenario both the company and its employee will be winners.

\section{DISCUSSION AND SUGGESTIONS}

To maximize positive employees behavioral intention to use a new information system, the likelihood of establishing positive employees attitude depends on positive interaction relationships in an employee's perceived usefulness and ease of use, company policy, and system quality.

This study suggests that when a company introduces or develops its own innovative information technology, it should emphasize the fitness between information technology and the users' duties. That is, an organizational promoter needs to understand user job characteristics and requirements in order to make the innovative information technology fit with the duties of users and expectation of customers, be able to simplify users' jobs and reduce their workload. Furthermore, the company needs to actively respond to employee feedbacks and in due course this improves employee willingness and confidence. By doing so, the system can be finely tuned and the potential users will increase their "perceived usefulness" and "perceived ease of use" toward the innovative information technology and then their usage intention will also rise.

\section{REFERENCES}

[1] F.D. Davis, A technology acceptance model for empirically testing new end-user information systems: theory and results. Unpublished doctoral dissertation, MIT Sloan School of Management, Cambridge, M.A., F.D., 1985.

[2] I. Ajzen, and M. Fishbein, Understanding attitudes and predicting social behavior. Englewood Cliffs. NJ: Prentice-Hall, 1980.

[3] M.Y. Chuttur, Overview of the technology acceptance model: Origins, developments and future directions. In M. Avital and K. Crowston (Eds.), Sprouts: Working papers on Information Systems (p1-21). 
Amsterdam Netherlands: University of Amsterdam, 2009.

[4] F.D. Davis, Perceived usefulness, perceived ease of use, and user acceptance of information technology. MIS Quarterly, 13(3), p319-340, 1989. http://dx.doi.org/10.2307/249008.

[5] R.P. Bagozzi, The legacy of the technology acceptance model and a proposal for a paradigm shift. Journal of the Association for Information Systems, 8(4), p244-254, 2007.

[6] V. Venkatesh, and F.D. Davis, A theoretical extension of the technology acceptance model: Four longitudinal field studies. Management Science, 46(2), p150-201, 2000. http://dx.doi.org/10.1287/mnsc.46.2.186.11926.

[7] F.D. Davies, R.P. Bagozzi, and P.R. Warshaw, User acceptance of computer technology: A comparison of two theoretical models. Management Science, 35(8), p982-1003, 1989. http://dx.doi.org/10.1287/mnsc.35.8.982.

[8] H. van der Heijden, Factors influencing the usage of Websites: The case of a generic portal in The Netherlands. Information \& Management, 40(6), p541-549, 2003. http://dx.doi.org/10.1016/S0378-7206(02)00079-4.

[9] V. Venkatesh, Creation of favorable user perceptions: Exploring the role of intrinsic motivation. MIS Quarterly, 23(2), p239-260, 1999. http://dx.doi.org/10.2307/249753.

[10] V. Venkatesh, M.G. Morris, G.B. Davis, and F.D. Davis, User acceptance of information technology: Toward a unified view. MIS Quarterly, 27(3), p425-478, 2003.

[11] W.W. Chin, and P.A. Todd, On the usefulness and ease of use of structural equation modeling in MIS research: a note of caution. MIS Quarterly, 19(2), p237-247, 1995. http://dx.doi.org/10.2307/249690.

[12] P.A. Pavlou, Consumer acceptance of electronic commerce. Integrating trust and risk with the technology acceptance model. International Journal of Electronic Commerce, 7(3), p101-134, 2003.

[13] S. Taylor, and P.A. Todd, Understanding information technology usage a test of competing models. Information Systems Research, 6(2), p144-176, 1995. http://dx.doi.org/10.1287/isre.6.2.144.

[14] T. Ryad, and B. Henri, Nonlinearities between attitude and subjective norms in information technology acceptance: A negative synergy? MIS Quarterly, 33(4), p830-844, 2009.

[15] V. Ventatesh, and F.D. Davies, A Model of antecedents of perceived ease of use: Development and test. Decision Science, 27(3), p451-481, 1996. http://dx.doi.org/10.1111/j.1540-5915.1996.tb00860.x.

[16] D.A. Adams, R.R. Nelson, and P.A. Todd, Perceived usefulness, ease of use, and usage of information technology: A replication. MIS Quarterly, 16(2), p227-247, 1992. http://dx.doi.org/10.2307/249577. 
[17] I. Ajzen, Attitude Structure \& Behavior. In A.R. Pratkanis, S.J. Breckler, and A.G. Greenwald (Eds.), Attitude structure and function (p241-274). New Jersey: Lawrence Erlbaum Assoclates, 1989.

[18] J. Hartwick, and H. Barki, Explaining the role of user participation in information system use. Management Science, 40(4), p440-465, 1994. http://dx.doi.org/10.1287/mnsc.40.4.440.

[19] J.C.C. Lin, and H. Lu, Towards an understanding of the behavioral intention to use a web site. International Journal of Information Management, 20(3), p197-208, 2000. http://dx.doi.org/10.1016/S0268-4012(00)00005-0.

[20] M. Simonson, M.A. Smaldino, and S. Zvacek, Teaching and learning at a distance: Foundations of distance. Upper Saddle River. NJ: Merrill, 2000.

[21] T.S.H. Teo, and W.Y. Choo, Assessing the impact of using the Internet for competitive intelligence. Information \& Management, 39(1), p67-83, 2001. http://dx.doi.org/10.1016/S0378-7206(01)00080-5.

[22] A. Rai, S.S. Lang, and R.B. Weiker, Assessing the validity of IS success model: An empirical test and theoretical analysis. Information Systems Research, 13(1), p50-69, 2002. http://dx.doi.org/10.1287/isre.13.1.50.96.

[23] S. M. Shareef, H. Jahankhani, and M. Dastbaz, E-government stage model: Based on citizen-centric approach in regional government in developing countries. International Journal of Electronic Commerce, 3(1), p145-164, 2012.

[24] R. Agarwal, and J. Prasad, Are individual differences germane to the acceptance of new information technologies? Decision Sciences, 30(2), p361-391, 1999. http://dx.doi.org/10.1111/j.1540-5915.1999.tb01614.x.

[25] P.B. Seddon, A respecification and extension of the DeLone and McLean model of IS Success. Information Systems Research, 8(3), p240-253, 1997. http://dx.doi.org/10.1287/isre.8.3.240.

[26] W. Hong, J.Y.L. Thong, W.M. Wong, and K.Y. Tam, Determinants of user acceptance of digital libraries: An empirical examination of individual differences and system characteristics. Journal of Management Information Systems, 18(3), p97-124, 2002.

[27] A. Lederer, D.J. Maupin, M.P. Senza, and Y. Zhuang, The technology acceptance model and the World Wide Web. Decision Support Systems, 29(3), p269-282, 2000. http://dx.doi.org/10.1016/S0167-9236(00)00076-2.

[28] G. Capece, and D. Campisi, User satisfaction affecting the acceptance of an e-learning platform as a mean for the development of the human capital. Behaviour \& Information Technology, 32(4), p335-343, 2013. http://dx.doi.org/10.1080/0144929X.2011.630417.

[29] T. Ahn, S. Ryu, and I. Han, The impact of online and offline features on 
the user acceptance of Internet shopping malls. Electronic Commerce Research and Applications, 3(4), p405-420, 2004. http://dx.doi.org/10.1016/j.elerap.2004.05.001.

[30] C. Ruth, Applying a modified technology acceptance model to determine factors affecting behavioral intention to adopt electronic shopping on the World Wide Web: A structural equation modeling approach. Doctoral dissertation, Drexel University, 2000.

[31] C.G. Bruner, and A. Kumar, Explaining consumer acceptance of handheld Internet devices. Journal of Business Research, 58(5), p553-558, 2005. http://dx.doi.org/10.1016/j.jbusres.2003.08.002.

[32] L. Chen, M.L. Gillenson, and D.L. Sherrell, Enticing online consumers: An extended technology acceptance perspective. Information \& Management, 39(8), p705-719, 2002. http://dx.doi.org/10.1016/S0378-7206(01)00127-6.

[33] Y. Park, H. Son, and C. Kim, Investigating the determinants of construction professionals' acceptance of web-based training: An extension of the technology acceptance model. Automation in Construction, 22(March), p377-386, 2012. http://dx.doi.org/10.1016/j.autcon.2011.09.016.

[34] H.D. Yang, and Y. Yoo, It's all about attitude: Revisiting the technology acceptance model. Decision Support Systems, 38(1), p19-31, 2004. http://dx.doi.org/10.1016/S0167-9236(03)00062-9.

[35] M. Turner, B. Kitchenham, P. Brereton, S. Charters, and D. Budgen, Does the technology acceptance model predict actual use? A systematic literature review. Information and Software Technology, 52(5), p463-479, 2010. http://dx.doi.org/10.1016/j.infsof.2009.11.005.

[36] H. Jeong, S. Han, and E. Lee, The role of psychological burden in mature consumers to adopt the internet. International Journal of Electronic Commerce Studies, 4(1), p135-138, 2013. http://dx.doi.org/10.7903/ijecs.1139.

[37] K. Mathieson, Predicting user intentions: Comparing the technology acceptance model with the theory of planned behavior. Information Systems Research, 2(3), p173-191, 1991. http://dx.doi.org/10.1287/isre.2.3.173.

[38] J.C. Anderson, and D.W. Gerbing, Structural equation modeling in practice: A review and recommended two-step approach. Psychological Bulletin, 103(3), p235-247, 1988. http://dx.doi.org/10.1037//0033-2909.103.3.411. 
